\title{
Glycated haemoglobin and cognitive decline: the Atherosclerosis Risk in Communities (ARIC) study
}

\author{
A. L. Christman • K. Matsushita • R. F. Gottesman • \\ T. Mosley • A. Alonso • J. Coresh • F. Hill-Briggs • \\ A. R. Sharrett $\cdot$ E. Selvin
}

Received: 19 November 2010 / Accepted: 27 January 2011 /Published online: 1 March 2011

(C) Springer-Verlag 2011

\begin{abstract}
Aims/hypothesis This study aimed to examine the association between diabetes and hyperglycaemia - assessed by $\mathrm{HbA}_{1 \mathrm{c}}$ - and change in cognitive function in persons with and without diabetes.

Methods This was a prospective cohort study of 8,442 nondiabetic and 516 diabetic participants in the Atherosclerosis
\end{abstract}

A. L. Christman $(\bowtie) \cdot$ K. Matsushita $\cdot$ J. Coresh • A. R. Sharrett •

E. Selvin

Department of Epidemiology, Bloomberg

School of Public Health, Johns Hopkins University,

615 North Wolfe Street,

Baltimore, MD 21205, USA

e-mail: andrea.christman@gmail.com

A. L. Christman · J. Coresh · F. Hill-Briggs • A. R. Sharrett •

E. Selvin

Welch Center for Prevention, Epidemiology,

and Clinical Research, Johns Hopkins University,

Baltimore, MD, USA

R. F. Gottesman

Department of Neurology,

Johns Hopkins University School of Medicine,

Baltimore, MD, USA

T. Mosley

Department of Medicine,

University of Mississippi Medical Center,

Jackson, MS, USA

A. Alonso

Division of Epidemiology and Community Health,

School of Public Health, University of Minnesota,

Minneapolis, MN, USA

F. Hill-Briggs

Department of Medicine,

Johns Hopkins University School of Medicine,

Baltimore, MD, USA
Risk in Communities (ARIC) study. We examined the association of baseline categories of $\mathrm{HbA}_{1 \mathrm{c}}$ with 6 year change in three measures of cognition: the digit symbol substitution test (DSST); the delayed word recall test (DWRT); and the word fluency test (WFT). Our primary outcomes were the quintiles with the greatest annual cognitive decline for each test. Logistic regression models were adjusted for demographic (age, sex, race, field centre, education, income), lifestyle (smoking, drinking) and metabolic (adiposity, blood pressure, cholesterol) factors. Results The mean age was 56 years. Women accounted for $56 \%$ of the study population and $21 \%$ of the study population were black. The mean $\mathrm{HbA}_{1 \mathrm{c}}$ was $5.7 \%$ overall: $8.5 \%$ in persons with and $5.5 \%$ in persons without diabetes. In adjusted logistic regression models, diagnosed diabetes was associated with cognitive decline on the DSST (OR 1.42, 95\% CI $1.14-1.75, p=0.002$ ), but $\mathrm{HbA}_{1 \mathrm{c}}$ was not a significant independent predictor of cognitive decline when stratifying by diabetes diagnosis (diabetes, $p$ trend $=0.320$; no diabetes, $p$ trend $=0.566$ ). Trends were not significant for the DWRT or WFT in either the presence or the absence of diabetes.

Conclusions/interpretation Hyperglycaemia, as measured by $\mathrm{HbA}_{1 \mathrm{c}}$, did not add predictive power beyond diabetes status for 6 year cognitive decline in this middle-aged population. Additional work is needed to identify the non-glycaemic factors by which diabetes may contribute to cognitive decline.

Keywords Cognition · Diabetes · Epidemiology ·

Haemoglobin $\mathrm{A}_{1 \mathrm{c}}$

$\begin{array}{ll}\text { Abbreviations } \\ \text { ARIC } & \text { Atherosclerosis Risk in Communities } \\ \text { DWRT } & \text { Delayed word recall test } \\ \text { DSST } & \text { Digit symbol substitution test } \\ \text { WFT } & \text { Word fluency test }\end{array}$


Diabetes is associated with an increased risk of cognitive decline and development of dementia [1-4]. However, the biological mechanisms linking diabetes to impaired cognition remain unclear. Individuals with diabetes are at increased risk for stroke, which is a risk factor for dementia, and it is also hypothesised that hyperglycaemia may contribute to microvascular changes and ischaemia in the brain $[5,6]$. Nonetheless, it remains unclear if hyperglycaemia is a predictor of cognitive decline independent of diabetes diagnosis.

$\mathrm{HbA}_{1 \mathrm{c}}$ is an integrated measure of circulating glucose levels over the preceding 2 to 3 months. $\mathrm{HbA}_{1 \mathrm{c}}$ is central to the management of glucose control in individuals with diagnosed diabetes and it has recently been recommended for use in the diagnosis of diabetes [7]. Epidemiological studies have demonstrated that $\mathrm{HbA}_{1 \mathrm{c}}$ is a risk factor for cardiovascular disease and total mortality among persons with and without diabetes $[6,8,9]$. Several previous studies have also reported an association between higher values of $\mathrm{HbA}_{1 \mathrm{c}}$ and poor cognitive function in persons with type 1 or type 2 diabetes [1]. However, few studies have investigated the association of hyperglycaemia with cognitive decline across the spectrum of glycaemia in persons with and without diabetes [10]. Previous studies have not investigated the association of $\mathrm{HbA}_{1 \mathrm{c}}$ with cognitive decline in a community-based population of persons with and without diabetes.

Our objective was to examine the association between $\mathrm{HbA}_{1 \mathrm{c}}$ and the 6 year change in cognitive function in middle-aged persons with and without diabetes in the Atherosclerosis Risk in Communities (ARIC) cohort. We sought to investigate if $\mathrm{HbA}_{1 \mathrm{c}}$ was an important determinant of cognitive function in both the overall population and in groups stratified by diabetes status. We also examined the association of $\mathrm{HbA}_{1 \mathrm{c}}$ with risk of hospitalisation with an ICD-9 code for dementia during 14 years of follow-up. We hypothesised that higher $\mathrm{HbA}_{1 \mathrm{c}}$ values in both persons with and without diabetes would be independently associated with the decline in cognitive function and risk of dementia hospitalisation.

\section{Methods}

Study population The ARIC study is an ongoing community-based prospective cohort of 15,792 middleaged adults from four US communities. The first visit occurred between 1987 and 1989 and there were three subsequent visits, occurring approximately 3 years apart. Cognitive functioning was assessed at two time points: visit 2 (1990-92) and again at visit 4 (1996-98). In the present analysis visit 2 was considered the baseline visit. We examined change in cognition from baseline to visit 4 over the 6 year period. Of the 11,656 participants who attended both visit 2 and visit 4 , we excluded those who were missing $\mathrm{HbA}_{1 \mathrm{c}}$ or cognitive test data or had test scores recorded out of range, who self-identified as other than white or black race, who had a history of stroke, or who scored in the bottom fifth percentile of one of the three cognitive tests at visit 2 [3], leaving 8,948 participants to be included in the final sample.

Assessment of diabetes and measurement of $\mathrm{Hb} A_{1 c}$ Diabetes history was defined based on a self-reported physician diagnosis of diabetes, fasting glucose value $\geq 7 \mathrm{mmol} / \mathrm{l}$, or diabetes medication use at or prior to visit 2 (baseline). Frozen whole-blood samples collected at ARIC visit 2 were thawed and assayed for $\mathrm{HbA}_{1 \mathrm{c}}$ measurement using highperformance liquid chromatography methods (Tosoh $\mathrm{A}_{1 \mathrm{c}}$ 2.2 Plus Glycohemoglobin Analyzer and Tosoh G7, Tosoh, Tokyo, Japan) [11]. We categorised $\mathrm{HbA}_{1 \mathrm{c}}$ using clinical cut-points set out in 2010 American Diabetes Association guidelines: in persons without a history of diabetes, $<5.7 \%$, $5.7-<6.5 \%, \geq 6.5 \%$; and in persons with a history of diabetes, $<7.0 \%, 7.0-8.0 \%$, and $\geq 8.0 \%$ [7].

Measures of cognitive function Three neuropsychological tests were used to assess cognitive function: the digit symbol substitution test (DSST) from the Wechsler adult intelligence scale-revised (WAIS-R), the delayed word recall test (DWRT), and the word fluency test (WFT), also known as the controlled oral word association test of the multilingual aphasia examination. Using identical protocols at visit 2 and visit 4 , trained examiners administered the neuropsychological tests in a standardised order during one session in a quiet room. Examiner performance was monitored by audiotape recordings, which were reviewed to ensure consistency.

The DSST is a test of executive function and processing speed. This is a timed test of translation of numbers to symbols using a key. The score is the total number of numbers correctly translated to symbols within $90 \mathrm{~s}$. Scores can range from 0 to 93 [12].

The DWRT is a test of verbal learning and recent memory. The study participant is asked to learn ten common nouns by using each word in two sentences. After a 5-min interval, the participant is asked to recall the ten nouns. The score is the number of nouns correctly recalled. The range of possible scores is 0 to 10 [13].

The WFT is a test of executive function and expressive language. The test includes three $1 \mathrm{~min}$ trials where the participant is asked to generate words beginning with a particular letter, not including proper names or places. The three letters used were ' $F$ ', ' $A$ ' and ' $S$ '. The score is the total number of correct words generated for the three trials [14]. 
Incident dementia hospitalisation ARIC investigators conduct active community-wide surveillance for all hospitalisations and deaths. We defined time to first hospitalisation with an ICD-9 code for dementia using the following ICD-9 codes (listed anywhere in the hospital discharge record): Alzheimer's disease (331.0), vascular dementia (290.4) or dementia of other aetiology $(290.0,290.1,290.2$, 290.3, 290.9, 294.1, 294.2, 294.8, 294.9, 331.1, 331.2, 331.8, 331.9) (www.icd9data.com/2011/Volume1/290-319/ 290-294/290/default.htm) [3].

Covariates All covariates used in the regression models were assessed during visit 2 (1990-1992), except education, which was assessed during visit 1 (1987-1989). Covariates evaluated as potential confounders included: age, race, field centre, sex, education ( $<$ high school; high school or vocational school; college, graduate, or professional school), family income ( $<$ US $\$ 35,000$ per year; $\geq U S \$ 35,000$ per year; not reported), BMI, cigarette smoking (current; former; never), drinking (current; former; never), systolic blood pressure, diastolic blood pressure, hypertension medication use and total cholesterol concentration.

Statistical analysis We computed the annual cognitive change for each person for each of the three tests. Change in cognitive function was calculated as the difference in days between the test scores at visit 4 and visit 2 divided by 365.25 to obtain the annual score change for each test. We then categorised the annual change in cognitive function into quintiles for each test. In our primary analyses, we compared the quintile with the largest annual decline with the other four quintiles.

Using multivariable linear regression, we estimated the cross-sectional associations between visit 2 cognitive test scores and $\mathrm{HbA}_{1 \mathrm{c}}$. We estimated adjusted odds ratios for the top quintile of annual cognitive decline and their $95 \%$ confidence intervals using multivariable logistic regression. Cox regression models were used to estimate adjusted hazard ratios for dementia hospitalisation. We considered two models that were adjusted as follows: model 1 was adjusted for age, race, field centre, sex, education and income; and model 2 was adjusted for all variables in model 1 plus BMI, smoking, drinking, systolic and diastolic blood pressures, hypertension medication use and total cholesterol concentration. We formally tested for interactions with race, sex and education. All models were evaluated overall (across the entire study population) and stratified by diabetes status to examine the association of $\mathrm{HbA}_{1 \mathrm{c}}$ with cognitive decline separately among persons with and without a history of diagnosed diabetes. We tested for trend across the median of the diabetes $-\mathrm{HbA}_{1 \mathrm{c}}$ categories. The $p$ value for trend represents linear trend of mean yearly change in test score across $\mathrm{HbA}_{1 \mathrm{c}}$ for no diabetes and diagnosed diabetes groups separately. The $p$ value for overall trend represents linear trend of mean yearly change in test score across $\mathrm{HbA}_{1 \mathrm{c}}$ categories for all participants (no diabetes and diagnosed diabetes combined).

In analyses of cognitive decline, we performed a sensitivity analysis excluding participants with incident stroke between visits 2 and $4(n=81)$. To assess possible survival bias, we evaluated the proportion of participants who died between visits 2 and 4 by diabetes-specific $\mathrm{HbA}_{1 \mathrm{c}}$ categories.

All reported $p$ values are two-sided and $p<0.05$ was considered statistically significant. Analyses were performed using Stata Version 11 [15].

\section{Results}

The demographic and clinical characteristics of the 8,958 study participants overall and stratified by diabetes $-\mathrm{HbA}_{1 \mathrm{c}}$ categories are shown in Table 1 . The mean age was 56 years, $56 \%$ were women and $21 \%$ were black. The mean $\mathrm{HbA}_{1 \mathrm{c}}$ was $5.7 \%$ overall: $8.5 \%$ in persons with and $5.5 \%$ in persons without diabetes.

In cross-sectional analyses of visit 2 cognitive test scores with $\mathrm{HbA}_{1 \mathrm{c}}$, an $\mathrm{HbA}_{1 \mathrm{c}}$ value higher by $1 \%$ was associated with a significantly lower score on DSST overall $(-0.43$, $95 \%$ CI $-0.63,-0.23, p<0.001)$ and when stratified by diabetes status (no diabetes: $p=0.02$, diabetes $p=0.05$ ). An $\mathrm{HbA}_{1 \mathrm{c}}$ value higher by $1 \%$ was associated with a -0.03 lower score on DWRT overall $(95 \%$ CI $-0.06,-0.003$, $p=0.28$ ) and with a -0.33 lower score on WFT overall (95\% CI $-0.55,-0.10, p=0.005)$. When stratified by diabetes status, cross-sectional associations between DWRT and WFT were not significantly associated with $\mathrm{HbA}_{1 \mathrm{c}}$ ( $p$ values $>0.06$ ).

The mean annual change in cognitive test score adjusted for age, race, sex and education by diabetes$\mathrm{HbA}_{1 \mathrm{c}}$ category is shown for each of the three cognitive tests in Fig. 1. In analyses adjusted for age, race, sex and education, the mean annual change in cognitive test score increased with increasing diabetes $-\mathrm{HbA}_{1 \mathrm{c}}$ category for all three cognitive tests in the overall population (DSST $p$ trend overall $<0.001$, DWRT $p$ trend overall $=0.032$, WFT $p$ trend overall $=0.005$ ), but not when stratified by diabetes diagnosis.

Expressing annual change in cognitive test scores in SD units enables comparison of the magnitude of the change across the tests. Participants experienced greater yearly decline on the DSST $(-0.39 \pm 1.00 \mathrm{SDs})$ compared with the DWRT $(-0.10 \pm 0.84$ SDs $)$ and the WFT $(-0.10 \pm 1.0$ SDs).

The adjusted odds ratios for the highest quintile of annual cognitive decline for each test are shown according to diabetes- $-\mathrm{HbA}_{1 \mathrm{c}}$ categories in Table 2. In the total 
Table 1 Characteristics of participants at ARIC visit 2 overall and by $\mathrm{HbA}_{1 \mathrm{c}}$ category and diabetes status

\begin{tabular}{|c|c|c|c|c|c|c|c|}
\hline \multirow[t]{2}{*}{ Characteristic } & \multirow{2}{*}{$\begin{array}{l}\text { All participants } \\
(N=8,958)\end{array}$} & \multicolumn{3}{|c|}{ Non-diagnosed diabetes } & \multicolumn{3}{|c|}{ Diagnosed diabetes } \\
\hline & & $\begin{array}{l}\mathrm{HbA}_{1 \mathrm{c}}<5.7 \% \\
(n=6,589)\end{array}$ & $\begin{array}{l}\mathrm{HbA}_{1 \mathrm{c}} 5.7-6.5 \% \\
(n=1,542)\end{array}$ & $\begin{array}{l}\mathrm{HbA}_{1 \mathrm{c}} \geq 6.5 \% \\
(n=311)\end{array}$ & $\begin{array}{l}\mathrm{HbA}_{1 \mathrm{c}}<7.0 \% \\
(n=144)\end{array}$ & $\begin{array}{l}\mathrm{HbA}_{1 \mathrm{c}} 7.0-8.0 \% \\
(n=107)\end{array}$ & $\begin{array}{l}\mathrm{HbA}_{1 \mathrm{c}} \geq 8.0 \% \\
(n=265)\end{array}$ \\
\hline Age (years) & $56.5 \pm 5.6$ & $56.2 \pm 5.6$ & $57.4 \pm 5.7$ & $57.3 \pm 5.5$ & $58.7 \pm 5.4$ & $58.4 \pm 5.9$ & $57.0 \pm 5.7$ \\
\hline Women, $n(\%)$ & $5,015(56.0)$ & $3,726(56.6)$ & $825(53.5)$ & $181(58.2)$ & $74(51.4)$ & $54(50.5)$ & $155(58.5)$ \\
\hline \multicolumn{8}{|l|}{ Race, $n(\%)$} \\
\hline White & $7,046(78.7)$ & $5,648(85.7)$ & $935(60.6)$ & $154(49.5)$ & $106(73.6)$ & $72(67.3)$ & $131(49.4)$ \\
\hline Black & $1,912(21.3)$ & $941(14.3)$ & $607(39.4)$ & $157(50.5)$ & $38(26.4)$ & $35(32.7)$ & $134(50.6)$ \\
\hline \multicolumn{8}{|l|}{ Education, $n(\%)$} \\
\hline$<$ High school & $1,344(15.0)$ & $776(11.8)$ & $348(22.6)$ & $88(28.3)$ & $33(22.9)$ & $34(31.8)$ & $65(24.5)$ \\
\hline $\begin{array}{l}\text { High school or } \\
\text { vocational school }\end{array}$ & $3,875(43.3)$ & $2,886(43.8)$ & $648(42.0)$ & $117(37.6)$ & $59(41.0)$ & $39(36.5)$ & $126(47.6)$ \\
\hline $\begin{array}{l}\text { College, graduate, or } \\
\text { professional school }\end{array}$ & $3,739(41.7)$ & 2,927 (44.4) & $546(35.4)$ & $106(34.1)$ & $52(36.1)$ & $34(31.7)$ & $74(27.9)$ \\
\hline \multicolumn{8}{|l|}{ Family income, $n(\%)$} \\
\hline$<\mathrm{US} \$ 35,000 /$ year & $4,087(45.6)$ & $2,717(41.2)$ & $850(55.1)$ & $199(64.0)$ & $82(56.9)$ & $66(61.7)$ & $173(65.3)$ \\
\hline$\geq \mathrm{US} \$ 35,000 /$ year & $4,392(49.0)$ & $3,530(53.6)$ & $601(39.0)$ & $88(28.3)$ & $56(38.9)$ & $37(34.6)$ & $80(30.2)$ \\
\hline Missing & $479(5.4)$ & $342(5.2)$ & $91(5.9)$ & $24(7.7)$ & $6(4.2)$ & $4(3.7)$ & $12(4.5)$ \\
\hline BMI $\left(\mathrm{kg} / \mathrm{m}^{2}\right)$ & $27.8 \pm 5.2$ & $27.0 \pm 4.7$ & $29.4 \pm 5.7$ & $32.0 \pm 5.9$ & $30.5 \pm 5.1$ & $31.4 \pm 6.4$ & $31.9 \pm 6.0$ \\
\hline \multicolumn{8}{|c|}{ Cigarette smoking status, $n(\%)$} \\
\hline Current smoker & $1,709(19.1)$ & $1,175(17.8)$ & $391(25.4)$ & $65(20.9)$ & $24(16.7)$ & $21(19.6)$ & $33(12.5)$ \\
\hline Former smoker & $3,472(38.8)$ & $2,571(39.0)$ & $573(37.2)$ & $122(39.2)$ & $59(41.0)$ & $45(42.1)$ & $102(38.5)$ \\
\hline Never smoker & $3,777(42.1)$ & $2,843(43.2)$ & $578(37.5)$ & $124(39.9)$ & $61(42.4)$ & $41(38.3)$ & $130(49.0)$ \\
\hline \multicolumn{8}{|l|}{ Alcohol use status, $n(\%)$} \\
\hline Current alcohol use & $5,399(60.3)$ & $4,260(64.7)$ & $813(52.7)$ & $129(41.5)$ & $70(48.6)$ & $46(43.0)$ & $81(30.6)$ \\
\hline Former alcohol use & $1,638(18.3)$ & $1,009(15.3)$ & $372(24.1)$ & $94(30.2)$ & $34(23.6)$ & $30(28.0)$ & $99(37.4)$ \\
\hline Never alcohol use & $1,918(21.4)$ & $1,317(20.0)$ & $357(23.2)$ & $88(28.3)$ & $40(27.8)$ & $31(30.0)$ & $85(32.1)$ \\
\hline $\mathrm{HbA}_{1 \mathrm{c}}(\%)$, median (IQR) & $5.4(5.2-5.8)$ & $5.3(5.1-5.5)$ & $5.9(5.8-6.1)$ & $6.8(6.6-7.2)$ & $6.3(5.8-6.6)$ & $7.4(7.2-7.7)$ & $9.8(8.9-10.9)$ \\
\hline Glucose (mmol/1) & $6.1 \pm 1.9$ & $5.6 \pm 0.6$ & $6.1 \pm 0.8$ & $8.1 \pm 2.4$ & $7.7 \pm 1.9$ & $10.1 \pm 2.3$ & $14.4 \pm 4.1$ \\
\hline Total cholesterol (mmol/l) & $5.4 \pm 1.0$ & $5.4 \pm 1.0$ & $5.5 \pm 1.0$ & $5.5 \pm 1.0$ & $5.3 \pm 1.0$ & $5.3 \pm 1.0$ & $5.6 \pm 1.1$ \\
\hline LDL-cholesterol (mmol/l) & $3.4 \pm 0.9$ & $3.4 \pm 0.9$ & $3.6 \pm 0.9$ & $3.6 \pm 1.0$ & $3.4 \pm 1.0$ & $3.4 \pm 0.9$ & $3.7 \pm 1.0$ \\
\hline HDL-cholesterol (mmol/l) & $1.3 \pm 0.4$ & $1.3 \pm 0.4$ & $1.2 \pm 0.4$ & $1.1 \pm 0.3$ & $1.1 \pm 0.4$ & $1.1 \pm 0.3$ & $1.1 \pm 0.4$ \\
\hline Triacylglycerols (mmol/l) & $1.4 \pm 0.7$ & $1.4 \pm 0.7$ & $1.5 \pm 0.7$ & $1.7 \pm 0.8$ & $1.7 \pm 0.8$ & $1.8 \pm 0.8$ & $1.9 \pm 0.9$ \\
\hline $\begin{array}{l}\text { Systolic blood pressure } \\
(\mathrm{mmHg})\end{array}$ & $120 \pm 17.6$ & $118 \pm 17.2$ & $123 \pm 17.8$ & $127 \pm 17.8$ & $129 \pm 19.2$ & $127 \pm 18.3$ & $127 \pm 18.9$ \\
\hline $\begin{array}{l}\text { Diastolic blood pressure } \\
\quad(\mathrm{mmHg})\end{array}$ & $72.0 \pm 9.9$ & $71.6 \pm 9.9$ & $73.1 \pm 10.0$ & $74.3 \pm 9.5$ & $72.0 \pm 9.5$ & $71.9 \pm 10.4$ & $72.0 \pm 9.9$ \\
\hline Hypertension, $n(\%)$ & $2,847(31.8)$ & $1,737(26.4)$ & 641 (41.6) & $168(54.0)$ & $87(60.4)$ & $69(64.5)$ & $146(55.1)$ \\
\hline \multicolumn{8}{|l|}{ Cognitive testing at visit 2} \\
\hline Digit symbol substitution & $47.4 \pm 12.8$ & $49.4 \pm 12.0$ & $42.9 \pm 13.5$ & $39.3 \pm 13.1$ & $44.6 \pm 12.6$ & $40.9 \pm 13.6$ & $38.7 \pm 13.7$ \\
\hline Delayed word recall & $6.9 \pm 1.4$ & $7.0 \pm 1.3$ & $6.7 \pm 1.3$ & $6.5 \pm 1.4$ & $6.5 \pm 1.3$ & $6.3 \pm 1.3$ & $6.5 \pm 1.5$ \\
\hline Word fluency & $35.4 \pm 11.5$ & $36.3 \pm 11.4$ & $33.4 \pm 11.6$ & $32.0 \pm 11.9$ & $34.3 \pm 11.5$ & $31.9 \pm 12.7$ & $31.0 \pm 10.6$ \\
\hline \multicolumn{8}{|l|}{ Cognitive testing at visit 4} \\
\hline Digit symbol substitution & $44.7 \pm 12.9$ & $46.7 \pm 12.0$ & $40.4 \pm 13.3$ & $36.9 \pm 13.2$ & $41.0 \pm 12.8$ & $36.5 \pm 15.1$ & $35.5 \pm 14.4$ \\
\hline Delayed word recall & $6.7 \pm 1.5$ & $6.8 \pm 1.5$ & $6.5 \pm 1.5$ & $6.1 \pm 1.6$ & $6.1 \pm 1.5$ & $6.0 \pm 1.8$ & $6.2 \pm 1.7$ \\
\hline Word fluency & $34.6 \pm 12.0$ & $35.5 \pm 11.8$ & $32.6 \pm 12.2$ & $31.5 \pm 11.4$ & $33.3 \pm 11.5$ & $29.0 \pm 13.7$ & $28.6 \pm 11.2$ \\
\hline \multicolumn{8}{|c|}{ Cognitive decline (visit 4-visit 2) } \\
\hline Digit symbol substitution & $-2.75 \pm 6.92$ & $-2.70 \pm 6.75$ & $-2.55 \pm 7.12$ & $-2.43 \pm 7.10$ & $-3.59 \pm 7.29$ & $-4.42 \pm 9.13$ & $-4.14 \pm 8.08$ \\
\hline Delayed word recall & $-0.18 \pm 1.52$ & $-0.15 \pm 1.50$ & $-0.19 \pm 1.54$ & $-0.41 \pm 1.57$ & $-0.36 \pm 1.40$ & $-0.31 \pm 1.67$ & $-0.33 \pm 1.69$ \\
\hline Word fluency & $-0.83 \pm 7.91$ & $-0.75 \pm 7.96$ & $-0.80 \pm 7.59$ & $-0.55 \pm 8.35$ & $-1.03 \pm 7.38$ & $-2.88 \pm 8.01$ & $-2.41 \pm 8.03$ \\
\hline
\end{tabular}

Values are mean \pm SD unless stated otherwise

$\mathrm{IQR}$, interquartile range 
Fig. 1 Mean yearly change in cognitive test scores by $\mathrm{HbA}_{1}$ category and diabetes status adjusted for age, race, sex and education: a DSST, overall trend $p<0.001 ;{ }^{\dagger} p=0.831 ;{ }^{\star} p=0.509$. b DWRT, overall trend $p<0.032 ;{ }^{\dagger} p<0.055$; ${ }^{\star} p=0.722$. c WFT, overall trend $p=0.005 ;{ }^{\dagger} p=0.231$ and ${ }^{\star} p=0.226$. The $p$ value for trend represents the linear trend of mean yearly change in test score across $\mathrm{HbA}_{1 \mathrm{c}}$ for no diabetes and diagnosed diabetes groups, separately. The $p$ value for overall trend represents the linear trend of mean yearly change in test score across $\mathrm{HbA}_{1 \mathrm{c}}$ categories for all participants (no diabetes and diagnosed diabetes combined). Error bars represent 95\% CI

population, we observed a significant association between baseline $\mathrm{HbA}_{1 \mathrm{c}}$ and cognitive decline assessed by the DSST (model 2, $p$ trend overall $=0.011$ ), which was probably driven by diagnosed diabetes. Diagnosed diabetes was associated with a 1.42 higher odds $(95 \%$ CI $1.14-1.75$, $p=0.002$ ) of cognitive decline on the DSST when comparing individuals with and without diagnosed diabetes. However, the association with $\mathrm{HbA}_{1 \mathrm{c}}$ was not significant when we stratified by diabetes status (diabetes, model 2, $p$ trend $=0.320$; no diabetes, model $2, p$ trend 0.556 ). In the total population, $\mathrm{HbA}_{1 \mathrm{c}}$ was not significantly associated with cognitive decline assessed by either the DWRT or the WFT in adjusted analyses (DWRT model 2, $p$ trend overall $=0.235$, WFT model $2, p$ trend overall $=0.169$ ). Similarly there was no significant association between cognitive decline and $\mathrm{HbA}_{1 \mathrm{c}}$ on the DWRT or WFT in analyses stratified by diabetes diagnosis (all $p$ trend $>0.2$ ). There was no significant interaction between sex, race or education for any of the three cognitive tests (all $p$ interaction $>0.1$ ). However, there was evidence of a stronger association between baseline $\mathrm{HbA}_{1 \mathrm{c}}$ and cognitive decline among blacks as compared with whites in this study. We observed borderline significant associations for both the DSST and DWRT in blacks in analyses stratified by race, although the $p$ for interaction by race was not statistically significant (DSST $p$ interaction model $2=0.822$; DWRT $p$ interaction model $2=0.103$ ).

There were 165 cases of incident hospitalisation with dementia listed as an ICD-9 code during a median of 14 years of follow-up for this outcome. A diagnosis of diabetes was associated with a $2.80(95 \%$ CI $1.83-4.30)$ times increased risk of dementia. Higher $\mathrm{HbA}_{1 \mathrm{c}}$ values at baseline were associated with an increased risk of dementia in the non-diabetes group (HR 0.92 [95\% CI $0.59-1.44$ ] and $\mathrm{HR} 2.68$ [95\% CI 1.46-4.91] for $\mathrm{HbA}_{1 \mathrm{c}} 5.7-<6.5 \%$ and $\geq 6.5 \%$ compared with $\mathrm{HbA}_{1 \mathrm{c}}<5.7 \%, p$ trend $=0.019$ ), but not within the diabetes group (HR 0.97 [95\% CI $0.37-$ 2.55] and 1.13 [95\% CI 0.43-2.98] for $\mathrm{HbA}_{1 \mathrm{c}} 7.0-<8.0 \%$ and $\geq 8.0 \%$ compared with $\mathrm{HbA}_{1 \mathrm{c}}<7.0 \%, p$ trend $=0.971$ ).

In sensitivity analyses of cognitive decline where participants who experienced incident stroke between visits 2 and 4 were excluded $(n=81)$, we found that the association for being in the top quintile of annual cognitive
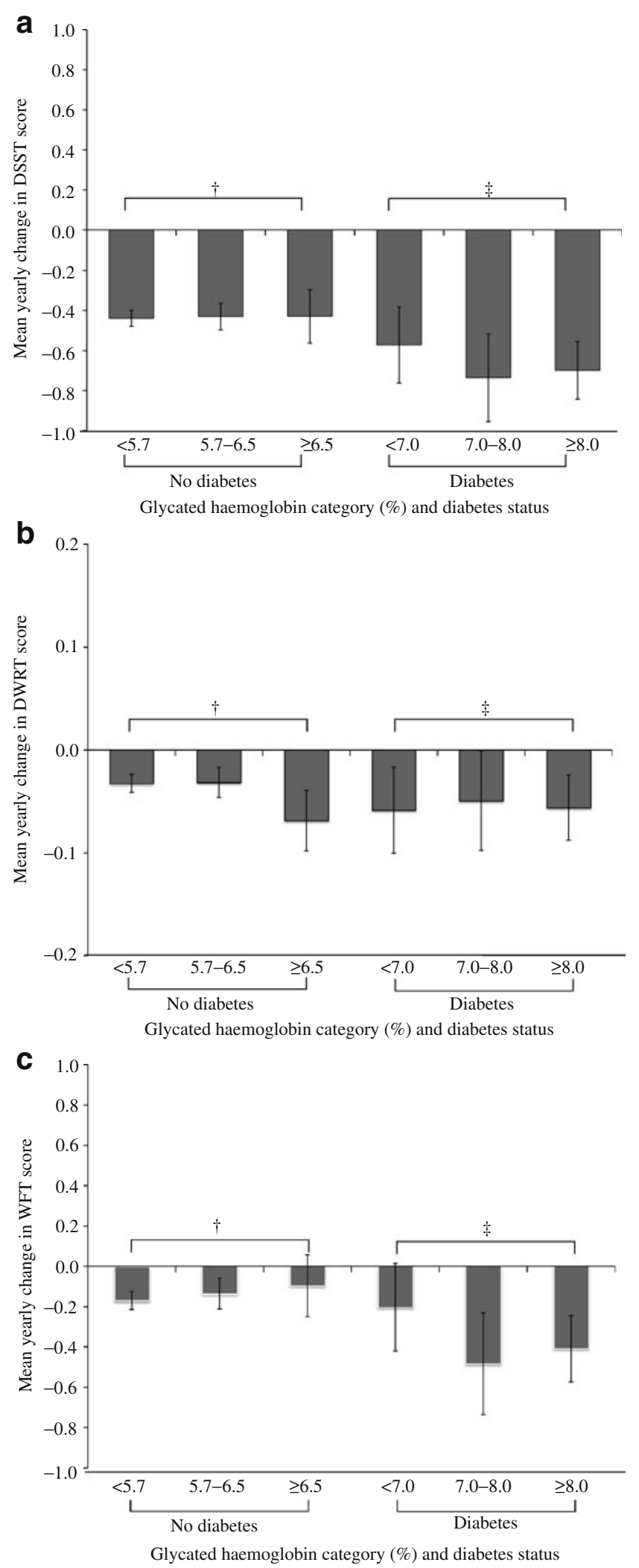
Table 2 Adjusted odds ratios for top quintile of yearly cognitive decline

\begin{tabular}{|c|c|c|c|c|c|c|}
\hline \multirow[t]{2}{*}{ Variable } & \multicolumn{2}{|l|}{ DSST } & \multicolumn{2}{|l|}{ DWRT } & \multicolumn{2}{|l|}{ WFT } \\
\hline & Model 1 & Model 2 & Model 1 & Model 2 & Model 1 & Model 2 \\
\hline Diagnosed diabetes (yes vs no) & $1.41(1.15-1.74)$ & $1.42(1.14-1.75)$ & $1.17(0.94-1.44)$ & $1.13(0.91-1.41)$ & $1.18(0.95-1.46)$ & $1.20(0.96-1.50)$ \\
\hline \multicolumn{7}{|l|}{ No diabetes } \\
\hline $\mathrm{HbA}_{1 \mathrm{c}}<5.7 \%$ (reference) & 1.00 & 1.00 & 1.00 & 1.00 & 1.00 & 1.00 \\
\hline $\mathrm{HbA}_{1 \mathrm{c}} 5.7-6.5 \%$ & $0.94(0.81-1.09)$ & $0.94(0.81-1.09)$ & $0.92(0.79-1.06)$ & $0.90(0.77-1.04)$ & $0.94(0.81-1.08)$ & $0.95(0.82-1.10)$ \\
\hline $\mathrm{HbA}_{1 \mathrm{c}} \geq 6.5 \%$ & $0.95(0.70-1.27)$ & $0.94(0.69-1.26)$ & $1.35(1.04-1.76)$ & $1.30(1.00-1.71)$ & $0.97(0.72-1.30)$ & $0.99(0.73-1.33)$ \\
\hline$p$ value for trend & 0.485 & 0.566 & 0.258 & 0.462 & 0.478 & 0.589 \\
\hline \multicolumn{7}{|l|}{ Diagnosed diabetes } \\
\hline $\mathrm{HbA}_{1 \mathrm{c}}<7.0 \%$ & $1.07(0.71-1.60)$ & $1.04(0.69-1.57)$ & $1.02(0.68-1.53)$ & $1.01(0.67-1.52)$ & $0.89(0.58-1.37)$ & $0.93(0.60-1.43)$ \\
\hline $\mathrm{HbA}_{1 \mathrm{c}} 7.0-8.0 \%$ & $1.82(1.19-2.78)$ & $1.78(1.15-2.74)$ & $1.46(0.95-2.24)$ & $1.40(0.90-2.16)$ & $1.37(0.88-2.14)$ & $1.41(0.90-2.22)$ \\
\hline $\mathrm{HbA}_{1 \mathrm{c}} \geq 8.0 \%$ & $1.41(1.06-1.88)$ & $1.34(1.00-1.81)$ & $1.14(0.85-1.53)$ & $1.08(0.80-1.46)$ & $1.22(0.91-1.65)$ & $1.22(0.90-1.66)$ \\
\hline$p$ value trend & 0.524 & 0.320 & 0.990 & 0.612 & 0.310 & 0.190 \\
\hline$p$ value for overall trend & 0.010 & 0.011 & 0.099 & 0.235 & 0.205 & 0.169 \\
\hline
\end{tabular}

Data are OR $(95 \% \mathrm{CI})$

Model 1 adjusted for age, race, sex, education, income and centre

Model 2 adds smoking, drinking, BMI, systolic blood pressure, diastolic blood pressure, hypertension medication use and total cholesterol $p$ value for trend represents linear trend of mean yearly change in test score across $\mathrm{HbA}_{1 \mathrm{c}}$ for no diabetes and diagnosed diabetes groups separately $p$ value for overall trend represents linear trend of mean yearly change in test score across $\mathrm{HbA}_{1 \mathrm{c}}$ categories for all participants (no diabetes and diagnosed diabetes combined)

decline for the DSST remained significant (adjusted OR 1.38 [95\% CI 1.02-1.88]), comparing persons with diabetes and $\mathrm{HbA}_{1 \mathrm{c}} \geq 8.0$ to persons without diabetes and $\mathrm{HbA}_{1 \mathrm{c}}<5.7$, $p$ trend overall $=0.045$. Our results for the DWRT and the WFT were not appreciably altered and remained nonsignificant (DWRT model $2, p$ trend overall $=0.313$, WFT model $2, p$ trend overall $=0.293$, data not shown).

There were 769 ARIC participants who died between visits 2 and 4 and there were 1,228 individuals who did not attend visit 4 and were not included in our analysis. In sensitivity analyses where the outcome was the top quintile of cognitive decline or death or loss to follow-up, there was no association with $\mathrm{HbA}_{1 \mathrm{c}}$ category for any of the three cognitive tests (all $p>0.5$ ). There were significantly higher percentages of deaths as the $\mathrm{HbA}_{1 \mathrm{c}}$ increased $(5.0 \%, 9.2 \%$, 9.6\%, $12.8 \%, 16.6 \%$ and $21.8 \%$ for $\mathrm{HbA}_{1 \mathrm{c}}$ categories $<5.7 \%, 5.7-<6.5 \%, \geq 6.5 \%,<7.0 \%, 7.0-8.0 \%$, and $\geq 8.0 \%$ ).

\section{Discussion}

To our knowledge, this is the first study of $\mathrm{HbA}_{1 \mathrm{c}}$ and cognitive decline in a community-based population of middle-aged adults. In the overall population (patients with and without diabetes combined), we found that $\mathrm{HbA}_{1 \mathrm{c}}$ was significantly associated with an increased risk of cognitive decline measured by the DSST, and this result appeared to be driven by a diagnosis of diabetes. That is, we did not observe an association between $\mathrm{HbA}_{1 \mathrm{c}}$ and cognitive decline when stratifying by diabetes history. Our findings are consistent with numerous studies that have demonstrated the association of diabetes with cognitive impairment [1] and with a prospective study of over 8,000 older adults in Europe, in which an association between baseline fasting glucose and 5 year cognitive change in non-diabetic adults was not observed [16]. Our study suggests that hyperglycaemia per se may not be the most important determinant of the elevated risk of cognitive impairment seen in diabetes.

Consistent with the literature and a previous ARIC report [3], we found that diabetes status was associated with decline on DSST, which reflects impairment in the executive function and processing speed domains of cognition [1, 4, 17]. Van den Berg et al. [18] also used the DSST and found decrements in information-processing speed, psychomotor speed and attention and executive functions in persons with diabetes compared with those without diabetes over 4 years of follow-up. A recent systematic review of diabetes and cognition found that $63 \%$ of studies that assessed the processing speed domain reported an association of diabetes with impairment in this domain [19]. Diabetes appears to strongly affect the processing speed, psychomotor speed and executive functioning, indicating that these domains may be particularly 
sensitive to the cognitive changes seen in diabetes [19]. The tests used in this study measure functions performed by different parts of the brain, with the DSST measuring subcortical function and the WFT and DWRT measuring cortical functions, indicating that hyperglycaemia may have a greater impact on the subcortical brain [19].

Most studies assessing the relationship between $\mathrm{HbA}_{1 \mathrm{c}}$ and cognitive function have been limited to persons with diabetes and have been cross-sectional, while our community-based prospective study included both persons with and without diabetes. Cukierman-Yaffe et al. [20] found a cross-sectional association whereby each $1 \%$ higher $\mathrm{HbA}_{1 \mathrm{c}}$ value was associated with a 1.75 point lower DSST score in the Action to Control Cardiovascular Risk in Diabetes-Memory in Diabetes (ACCORD-MIND) study baseline population (mean age 63 years). We observed a similar cross-sectional association on the DSST in the ARIC population of middle-aged adults with and without diabetes, both overall and when stratified. We did not, however, observe an independent association between $\mathrm{HbA}_{1 \mathrm{c}}$ and 6 year cognitive decline in our prospective analyses stratified by diabetes status. This null result may partially reflect the middle-aged population and short duration of follow-up. Indeed, the absolute levels of cognitive change over this 6 year period were small. In addition, differential survival may have also biased our results toward the null, as the 769 ARIC participants who died between visits 2 and 4 were more likely to have higher baseline $\mathrm{HbA}_{1 \mathrm{c}}$, a history of diagnosed diabetes, and may have had greater cognitive declines prior to death.

None of race, sex or education significantly modified the associations between $\mathrm{HbA}_{1 \mathrm{c}}$ and cognitive decline in our study. However, in analyses stratified by race, we observed borderline significant associations between cognitive decline on both the DSST and DWRT in blacks only.

We did not find any significant association between diabetes or $\mathrm{HbA}_{1 \mathrm{c}}$ and cognitive decline on either the WFT or the DWRT. Our weaker results for WFT and DWRT may reflect the short duration of follow-up and the small absolute changes in cognition in this population of middle-aged adults. Our results cannot exclude the possibility that $\mathrm{HbA}_{1 \mathrm{c}}$ is an important predictor of cognitive decline at older ages and/or over longer follow-up.

Previous analyses of ARIC data demonstrated a strong association of diabetes and cognition with incident dementia hospitalisation [3]. We also found that in participants without a history of diabetes, $\mathrm{HbA}_{1 \mathrm{c}} \geq 6.5 \%$ was associated with incident dementia hospitalisation, probably driven by the extremely high cumulative incidence $(>80 \%)$ of a subsequent diagnosis of diabetes in this group [9, 21]. Among individuals with diagnosed diabetes, $\mathrm{HbA}_{1 \mathrm{c}}$ was not independently associated with risk of dementia hospitalisation in this study.
A number of mechanisms have been postulated to explain how diabetes and hyperglycaemia contribute to cognitive decline. First, AGEs accumulate both during the normal ageing process and more rapidly with hyperglycaemia and diabetes [22]. AGEs cause tissue damage generally, and perhaps in cerebral vessels specifically, both by forming cross-links that disrupt the structure and function of proteins and lipids and by interacting with AGE surface receptors, leading to oxidative stress and inflammation [23]. Hyperinsulinaemia may also increase the risk of cognitive impairment and dementia by interfering with amyloid precursor protein metabolism, and possibly promoting the cerebral $\beta$-amyloid deposits characteristic of Alzheimer's disease. Hyperinsulinaemia may contribute to microvascular damage leading to cerebral infarcts and atrophy [23].

Important limitations of our study include a limited cognitive test battery, lack of data on hypoglycaemic events, and the reliance on a single measurement of $\mathrm{HbA}_{1 \mathrm{c}}$ at baseline. We may have had limited power to detect associations between $\mathrm{HbA}_{1 \mathrm{c}}$ and cognitive decline as we did not observe large changes in cognition during the 6 year period in this community-based middle-aged population [24]. Although our study population had a mean age of 56 years and the prevalence of substantial cognitive decline in this community-based population was low, other studies using this cohort have found significant associations with other vascular risk factors and cognitive decline over this time period [3].

The strengths of this study include the comprehensive assessment of diabetes risk factors, large sample size, and two assessments of cognition. This study adds to our knowledge of the association of $\mathrm{HbA}_{1 \mathrm{c}}$ with cognition across the entire spectrum of glycaemia in persons with and without diabetes.

In summary, hyperglycaemia, as measured by $\mathrm{HbA}_{1 \mathrm{c}}$, did not predict 6 year cognitive decline beyond diabetes status in this middle-aged community-based population. In this prospective study, diabetes itself was associated with decline in one cognitive domain (executive function and processing speed) but higher values of baseline $\mathrm{HbA}_{1 \mathrm{c}}$ were not independently associated with cognitive decline over a 6 year period in persons either with or without diabetes. Future studies should help identify the non-glycaemic risk factors by which diabetes contributes to cognitive decline.

Acknowledgements This research was supported by NIH/NIDDK grant R21 DK080294. E. Selvin was also supported by NIH/NIDDK grant K01 DK076595. A. L. Christman was also supported by NIH/NIDDK training grant T32 DK062707. F. Hill-Briggs was supported by NIH/NIDDK Diabetes Research and Training Center grant P60 DK079637. The Atherosclerosis Risk in Communities Study is carried out as a collaborative study supported by National Heart, Lung, and Blood Institute contracts N01-HC-55015, N01-HC55016, N01-HC-55018, N01-HC-55019, N01-HC-55020, N01-HC55021, and N01-HC-55022. 
Duality of interest The authors declare that there is no duality of interest associated with this manuscript.

\section{References}

1. Biessels GJ, Staekenborg BE, Brayne C, Scheltens P (2006) Risk of dementia in diabetes mellitus: a systematic review. Lancet Neurol 5:64-74

2. Cukierman T, Gerstein HC, Williamson JD (2005) Cognitive decline and dementia in diabetes - systematic overview of prospective observational studies. Diabetologia 48:2460-2469

3. Alonso A, Mosley TH Jr, Gottesman RF, Catellier D, Sharrett AR, Coresh J (2009) Risk of dementia hospitalisation associated with cardiovascular risk factors in midlife and older age: the Atherosclerosis Risk in Communities (ARIC) study. J Neurol Neurosurg Psychiatry 80:1194-1201

4. Knopman DS, Mosley TH, Catellier DJ, Coker LH (2009) Fourteenyear longitudinal study of vascular risk factors, APOE genotype, and cognition: the ARIC MRI Study. Alzheimers Dement 5:207-214

5. Folsom AR, Rasmussen ML, Chambless LE et al (1999) Prospective associations of fasting insulin, body fat distribution, and diabetes with risk of ischemic stroke. The Atherosclerosis Risk in Communities (ARIC) Study Investigators. Diabetes Care 22:1077-1083

6. Selvin E, Coresh J, Shahar E, Zhang L, Steffes M, Sharrett AR (2005) Glycaemia (haemoglobin $\mathrm{A}_{1 \mathrm{c}}$ ) and incident ischaemic stroke: the Atherosclerosis Risk in Communities (ARIC) Study. Lancet Neurol 4:821-826

7. Association AD (2010) Diagnosis and classification of diabetes mellitus. Diabetes Care 33(Suppl 1):S62-S69

8. Levitan EB, Song Y, Ford ES, Liu S (2004) Is nondiabetic hyperglycemia a risk factor for cardiovascular disease? A metaanalysis of prospective studies. Arch Intern Med 164:2147-2155

9. Selvin E, Steffes MW, Zhu H et al (2010) Glycated hemoglobin, diabetes, and cardiovascular risk in nondiabetic adults. N Engl J Med 362:800-811

10. Yaffe K, Blackwell T, Whitmer RA, Krueger K, Barrett Connor E (2006) Glycosylated hemoglobin level and development of mild cognitive impairment or dementia in older women. J Nutr Health Aging 10:293-295

11. Selvin E, Coresh J, Zhu H, Folsom AR, Steffes MW (2010) Measurement of glycated hemoglobin from stored whole blood samples in the Atherosclerosis Risk in Communities study. J Diabetes 2:118-124

12. Wechsler D (1981) Wechsler Adult Intelligence Scale-Revised Manual. Psychological Corp, New York

13. Knopman DS, Ryberg S (1989) A verbal memory test with high predictive accuracy for dementia of the Alzheimer type. Arch Neurol 46:141-145

14. Benton AL, Hamsher K (1989) Multilingual aphasia examination, 2nd edn. AJA Associates, Iowa City

15. (2009) Stata Statistical Software: Release 11. StataCorp, College Station, TX

16. Euser SM, Sattar N, Witteman JC et al (2010) A prospective analysis of elevated fasting glucose levels and cognitive function in older people: results from PROSPER and the Rotterdam Study. Diabetes 59:1601-1607

17. Knopman D, Boland LL, Mosley T et al (2001) Cardiovascular risk factors and cognitive decline in middle-aged adults. Neurology $56: 42-48$

18. van den Berg E, Reijmer YD, de Bresser J, Kessels RP, Kappelle LJ, Biessels GJ (2010) A 4 year follow-up study of cognitive functioning in patients with type 2 diabetes mellitus. Diabetologia 53:58-65

19. van den Berg E, Kloppenborg RP, Kessels RP, Kappelle LJ, Biessels GJ (2009) Type 2 diabetes mellitus, hypertension, dyslipidemia and obesity: a systematic comparison of their impact on cognition. Biochim Biophys Acta 1792:470-481

20. Cukierman-Yaffe T, Gerstein HC, Williamson JD et al (2009) Relationship between baseline glycemic control and cognitive function in individuals with type 2 diabetes and other cardiovascular risk factors: the action to control cardiovascular risk in diabetes-memory in diabetes (ACCORD-MIND) trial. Diabetes Care 32:221-226

21. Selvin E, Steffes MW, Gregg E, Brancati FL, Coresh J (2010) Performance of glycated hemoglobin for the classification and prediction of diabetes. Diabetes Care 34:84-89

22. Monnier VM, Sell DR, Genuth S (2005) Glycation products as markers and predictors of the progression of diabetic complications. Ann NY Acad Sci 1043:567-581

23. Peppa M, Vlassara H (2005) Advanced glycation end products and diabetic complications: a general overview. Hormones (Athens) 4:28-37

24. Qiu C, De Ronchi D, Fratiglioni L (2007) The epidemiology of the dementias: an update. Curr Opin Psychiatry 20:380-385 